\title{
Musyāfahah al-Qur’ān Melalui Media Elektronik
}

\section{Apakah ketika musyāfahah al-Qur'ān dilakukan melalui media elektronik (termasuk secara daring) dapat memenuhi kriteria talaqqī sesuai ketentuan dalam Ilmu Qirō’at?}

Ilmu Qirō`at adalah ilmu tentang tata cara membaca (me-lafaz-kan) dengan tepat kata-kata dalam al-Qur'ān beserta ragam perbedaan dengan atribusi perpindahan silsilah bacaan. ${ }^{1}$ Orang yang mengerti tentang qirō 'at yang diriwayatkan melalui musyāfahah secara talaqqī dari guru sampai kepada Rosūlillāh Muḥammad șollalōhu'alayhiwasallam disebut muqri . ${ }^{2}$ Shaykh al-Qurrō’ Muḥammad ibn Muḥammad ibn Muḥammad al-Jazar̄̄ menuturkan bahwa seandainya ada seseorang yang hafal al-Taisīr, tetap tidak boleh mengajarkan ilmu Qirō’at selama belum musyāfahah kepada guru yang sanadnya bersambung sampai kepada Rosūlillāh Muhammad șollalōhu'alayhiwasallam. ${ }^{3}$ Ketidakbolehan ini karena dalam ilmu Qirō’at terdapat banyak yang tidak bisa di-ḥukm-i kecuali dengan menyimak langsung dan musyāfahah. ${ }^{4}$ Misalnya terkait pe-lafaz-an rō` bagi orang yang cadel. al-Taisīr yang dimaksud oleh al-Jazarī ialah Kitāb al-Taisīr fì al-Qirō 'àt al-Sab' karya 'Utsmān ibn Sa'̄̄d ibn 'Utsmān al-Dān̄̄ yang mengurai rangkuman tujuh ragam bacaan al-Qur'an. ${ }^{5}$ al-Jazarī sendiri disebut oleh Jalāl al-Dīn 'Abd al-Raḥmān ibn Abī Bakr al-Suyūṭ̄ sebagai otoritas tertinggi dalam masalah Ilmu Qirō at. ${ }^{6}$ Lebih lanjut al-Jazarī menyampaikan bahwa dalam Qirō’at terdapat toleransi, yang hanya berlaku kepada orang yang lisannya memang tidak mampu (misalnya cadel) serta orang yang tidak menemukan guru yang menuntunnya kepada keterangan yang tepat. ${ }^{7}$

$$
\begin{aligned}
& \text { ' القر اءات علم بكيفية أداء كلمات القر آن و اختلافها بعزو الناقلة (الجزري، } 999 \text { (، صفحة 9) } \\
& \text { ' و المقرئ العالم بهاور اها مشافهة (الجزري، } 999 \text { (1، صفحة 9) } \\
& \text { ` فلو حفظ "التيسير" مثنلا ليس لله أن يقرئ بما فيه إن لم يثافهه من شوفه به مسلسلا (الجزري، } 999 \text { ( ، صفحة 9) } \\
& \text { ؛ لأن في القر اءات أثياء لا تحكم إلا بالسماع و المشافهة (الجزري، } 999 \text { (1، صفحة 9) }
\end{aligned}
$$

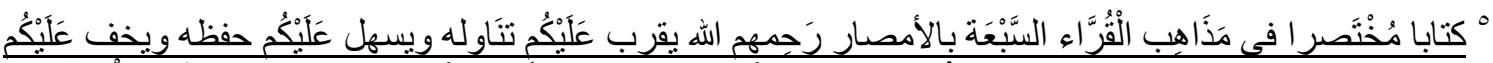

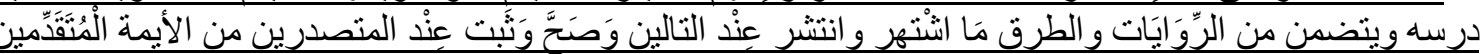

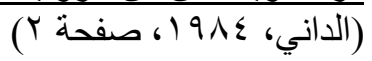

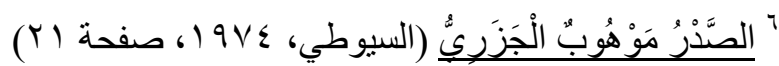

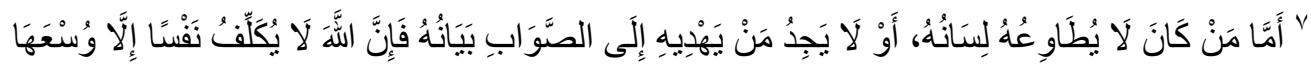

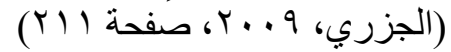


Informasi tersebut menunjukkan bahwa Ilmu Qirō’at berdasar kepada talaqq̄̄ dari lisan muqri dan tidak bisa hanya dari kitab saja. ${ }^{8910}$ Pada masa sekarang, kitab juga dapat disamakan dengan media lain, seperti audio dan video.

Naș al-Qur'ān yang dijadikan dasar keharusan talaqqī ialah ayat 6 al-Naml yang menceritakan tentang talaqi-nya Rosūlillāh Muḥammad ṣollalōhu'alayhiwasallam kepada Allōh subḥānahuwata'ālā melalui Jibrīl ‘alayhissalām:

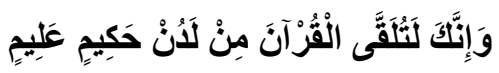

yang dapat dialihbahasakan ke dalam Bahasa Indonesia ${ }^{111213}$ :

“Sesungguhnya kamu benar-benar diberi al-Qur'ān dari sisi Yang Maha

Bijaksana lagi Maha Mengetahui.”

^ اعلم - بر حمك الله ـ أن هذا العلم العظيم لا يؤخذ من كتاب و لا من مصحف دون معلم، و لا بد من التلقي و المشافهة؛ وهو

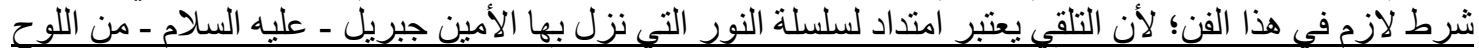

المحفوظ، على قلب الحبيب ـ صلّي الله عليه و وسلم - وقد أخذه النبي ـ صلّي الله عليه وسلم - منه مشافهة، و هكذا منه إلينا

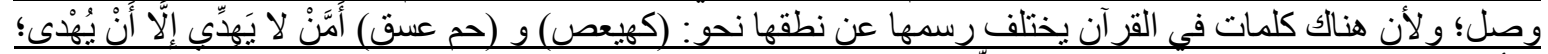

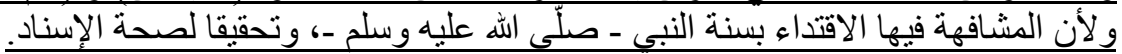

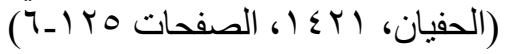

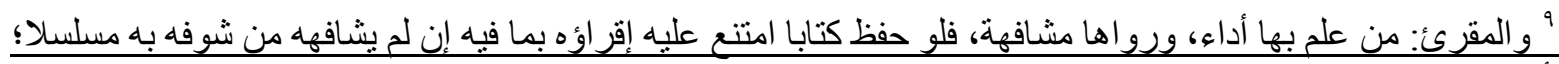

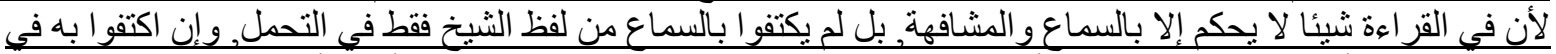

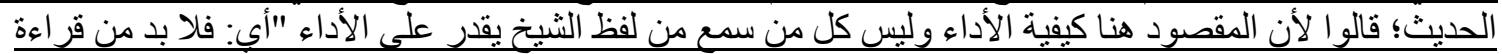

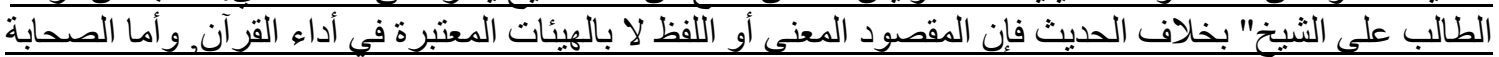

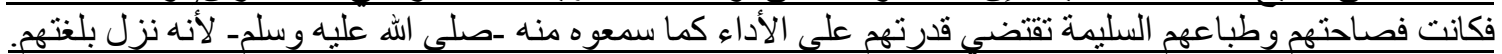

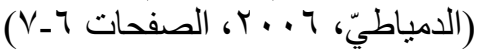

' ' ومما يجب التنبه لله أن التجويد العملي لا يمكن أن يؤخذ من المصحف مهما بلغ من الضبط و الإجادة، و لا يمكن أن يُتعلد

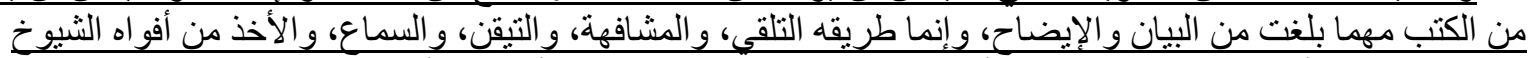

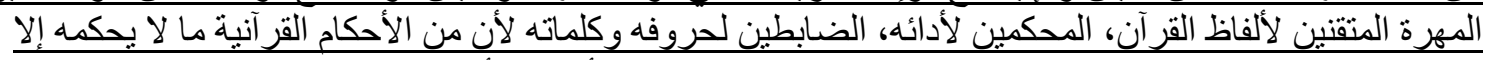

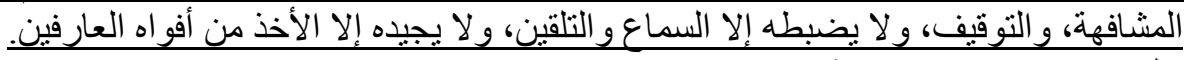

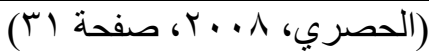

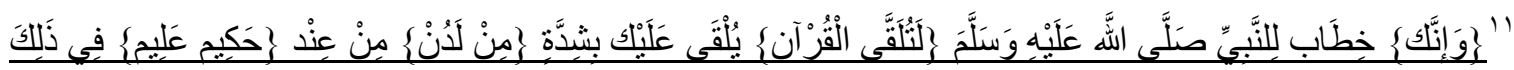

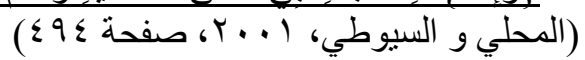

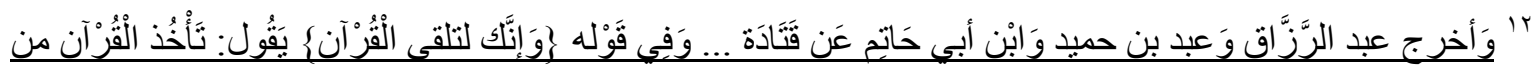

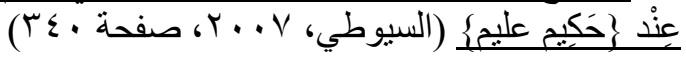

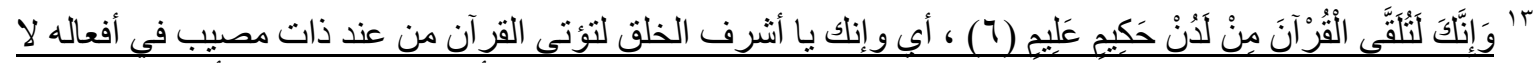

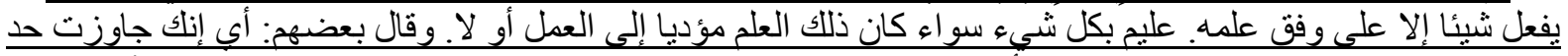

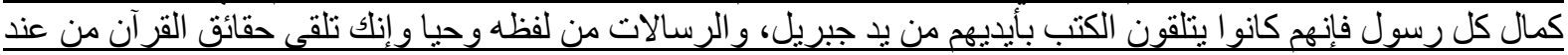

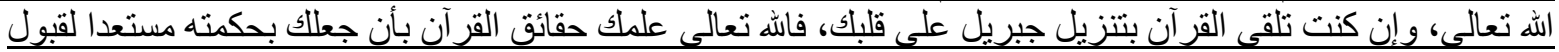

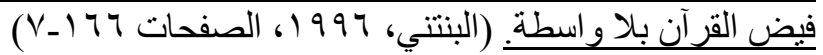


Sementara naṣ al-Qur'ān yang dijadikan dasar musyāfahah ialah ayat 18 al-Qiyāmah yang menceritakan bahwa Rosūlullōh Muḥammad șollalōhu'alayhiwasallam menyimak bacaan kemudian membacakannya kembali:

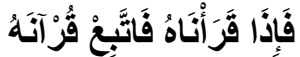

yang dapat dialihbahasakan ke dalam Bahasa Indonesia ${ }^{141516}$ :

"Ketika Kami telah selesai membacakannya, maka ikutilah bacaannya itu."

Naṣ lain yang dijadikan dasar talaqqī dan musyāfahah ialah al-ḥadīts tentang instruksi Rosūlullōh Muhammad șollalōhu'alayhiwasallam agar mengambil bacaan al-Qur'ān dari qōri yang dapat dijumpai. ${ }^{17}$ Selain naṣ al-Qur’ān dan al-ḥadīts, terdapat informasi sejarah ketika masa kodifikasi al-Qur'ān, 'Utsmān ibn 'Affān roḍiyallōhu'anhu mendampingkan muqri' bagi setiap mușhaf resmi 'Utsmānī yang dikirimkan ke beberapa daerah. ${ }^{18}$

Dalam ilmu Qirō’at, pe-lafaz-an bacaan al-Qur'ān yang dapat diterima memiliki 3 kriteria utama:

1. sesuai dengan kerangka bunyi mușhaf resmi 'Utsmānī;

2. konsisten dengan tata bahasa Arab; serta

3. terdapat rantai transmisi otentik (sanad).

Bacaan yang tidak tidak memenuhi ketiga kriteria ini disebut $s y \bar{a} d z$ (anomali / tidak teratur). Bacaan syādz tidak boleh dipraktikkan (di-'amal-kan), walau dapat dipelajari secara akademis, misalnya untuk kajian ilmu Sejarah atau Tafsīr.

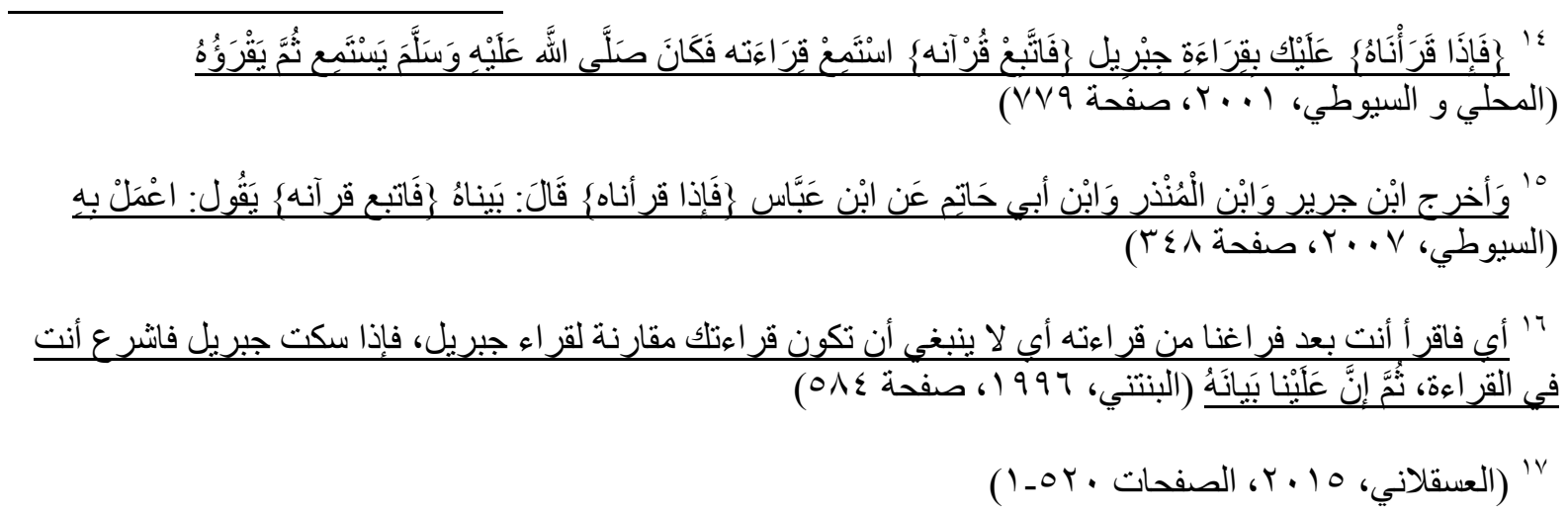

${ }^{18}$ (Geissinger, 2017, hal. 441-2) 
Mengamati fenomena yang terjadi pada masa ini, orang yang tidak musyāfahah al-Qur'ān dapat diklasifikasi menjadi 4 kategori:

1. Menguasai Ilmu Qirō’at dari membaca kitab saja tanpa melihat dan mendengarkan bacaan muqri dalam bentuk apapun serta tidak pernah musyāfahah sama sekali. Meskipun cara ini memungkinkan orang untuk dapat membaca al-Qur'ān, tidak terdapat talaqqī antara guru dan murid. Sehingga orang dalam ketgori ini tidak bisa disebut qōri`, melainkan muṣōfí al-qirō `at (orang yang bagus dalam bacaan).

2. Mendengarkan bacaan muqri dari audio (murottal), disamakan seperti belajar dari kitab yang sekadar sebagai penolong tanpa bisa menggugurkan kewajiban talaqqī. Ini terjadi karena murid tidak berkesempatan mengamati gerakan bibir guru, seiring hanya melalui media suara dan/atau tulisan.

3. Melihat dan mendengarkan video praktik pengucapan musyāfahah-baik berupa tutorial dari muqri atau bacaan yang bersifat populer saja. Cara ini tidak memenuhi kriteria talaqq $\bar{l}$, sebab guru tidak bisa mengamati gerakan bibir-termasuk membenahi pe-lafaz-an yang salah dari bacaan murid, itupun kalau murid mempraktikkan.

4. Menyimak, mendengarkan, memperagakan, dan memperbaiki bacaan melalui media video-baik video call maupun kiriman rekaman video. Kategori ini memungkinkan murid untuk dapat berkesempatan mengerti gerakan bibir guru dan memperlihatkan praktik pe-lafaz-an kepada guru serta guru bisa menyimak dan membenahi ketika terdapat kesalahan pe-lafaz-an dari bacaan murid ketika mempraktikkan.

Dengan demikian, dari keempart kategori tersebut, hanya kategori keempat yang masih dapat memenuhi kriteria talaqqī. Walau begitu, video ini harus memperhatikan pencahayaan yang tepat dan akses suara yang jelas serta sinyal kuat khusus untuk video call. Ini diperlukan agar proses pelaksanaan dapat hampir sama persis dengan talaqqī secara tatap muka seperti biasa. Selain itu, demi keberkahan sanad yang menyambung sampai kepada Rosūlillāh Muḥammad șollalōhu'alayhiwasallam serta peng-ijazāh-an sanad mengajarkan al-Qur'ān, lebih baiknya minimal saat khataman tetap bertatap muka secara luring.

$-\Lambda \mathrm{RS}$

wallōhu a'lam bi al-ṣowāb

K.Ah.Lg.250841.180420.23:33 


\section{Referensi}

Geissinger, A. (2017, Januari 4). No, a Woman Did Not "Edit the Qur'ān": Towards a

Methodologically Coherent Approach to a Tradition Portraying a Woman and Written

Quranic Materials*. Journal of the American Academy of Religion, 85(2), 416-445.

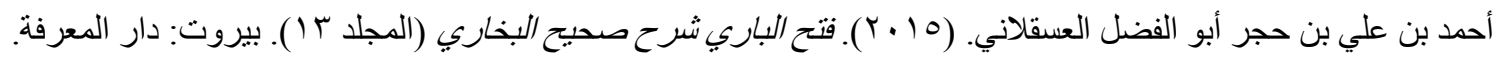

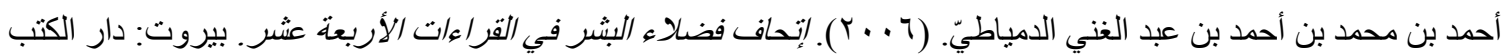
العلمية.

أحمد محمود عبد السميع الثافعى الحفيان. ( آ؟ ()). الوافي في كبفية ترتيل القرآن الكريم (شرح واف لكتني الجزرية وتحفة الأطفال). بيروت: دار الكتب العلمية.

جلال الدين عبد الرحمن بن أبي بكر السيوطي. ( \& 19V) الإتقان في علوم القرآن (المجلد ع). القاهرة: الهيئة المصرية العامة للكتاب.

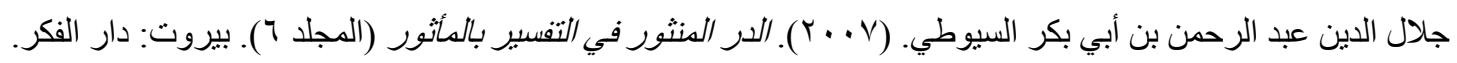

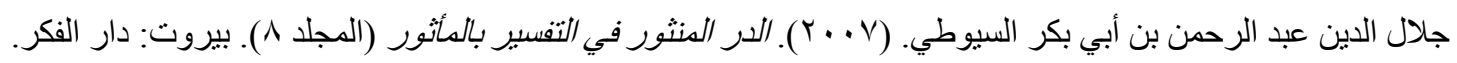

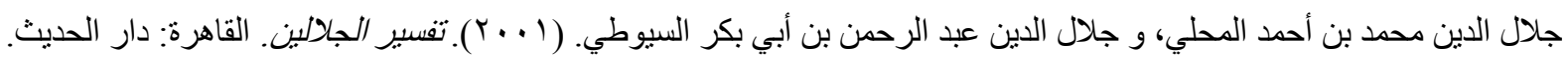

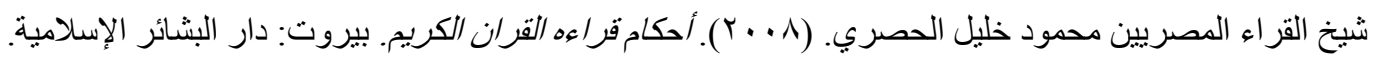

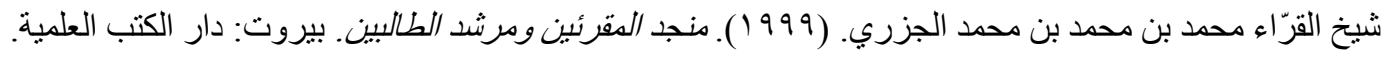

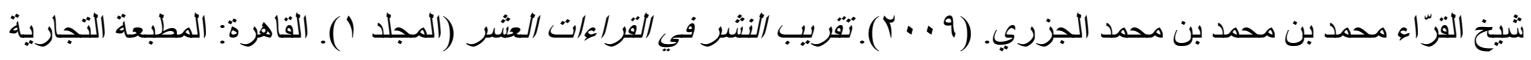
الكبرى. عثمان بن سعيد بن عثمان الداني. (ع 9 (1). التنبسير في القراءات. بيروت: دار الكتاب العربي.

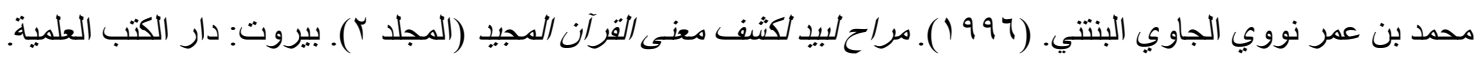

